\title{
SOLUTION OF TRAVELLING SALESMAN PROBLEM FOR WHOLESALE OUTLAYS CONSIDERING REPEATED VISITATION OF CERTAIN SALES OUTLETS
}

\author{
Nataliia Matsiuk \\ Bukovynian State Finance and Economics University, Chernivtsi, Ukraine
}

(c) MESTE NGO

JEL Classification: C02, C61

\begin{abstract}
This paper presents the solving of the travelling salesman problem with repeated visitation of several outlets. The genetic algorithm was used as a technique for the finding the shortest route in the case of visiting every destination point. The three cases are described in the present research: the solving of the Euclidean travelling salesman problem, the solving of the travelling salesman problem considering the region transportation network and the solving of the travelling salesman problem with repeated visitation of some sales outlets. The solving algorithm which involves partitioning the route into sections without repeated visits to sales outlets has been proposed. Obtained results were combined into one which was considered as optimized for a given route. As a result of our investigation we have proposed the optimized routes that are up to $29 \%$ shorter than the actual ones used by the wholesale trade enterprises. As we can see this methodology provides a significant reduction of the transportation expenses of such organizations.
\end{abstract}

Keywords: travelling salesman problem, genetic algorithm, near optimal route, wholesale outlays

\section{INTRODUCTION}

Maintenance and advancement of sales outlet's competitive position on the market is one of the main conditions of its existence and successful functioning at the present stage of economy development. It is obvious that formation of longterm stable competitive advantages of business is impossible without complex analysis of the suppliers, consumers, resellers and competitors.

Address of the author:

Nataliia Matsiuk

麦=- chernova_n@i.ua
However, the basic attention of the company management should be paid to increasing the internal efficiency of the enterprise. This becomes possible due to the decrease of current expenditure that is the greatest part of operational activities expenses for a wholesale mercantile business. The problem of decreasing current expenses, particularly the transportation ones, is analyzed in this research for the group of enterprises of Chernivtsi oblast of Ukraine that deal with wholesale trade.

As the majority of such businesses arrange interaction with retail companies with the help of 
travelling sales agents, the problem of minimizing their transportation expenses is similar to the classical travelling salesman problem (TSP).

The TSP has proven to become classical since it was first mathematically formulated by Karl Menger in 1930, about a century ago. Among the publications devoted to this subject (Goodman \& Hedetniemi, 1977) should be mentioned. The problem statement and several algorithms of its solution are presented in it. Nowadays the solution of this problem has rather a theoretical value for the scientists than a practical one, as it serves as the basis for developing new optimization algorithms, for instance, (Bi, Dong, \& Ma, 2012). Still, the practical side of the TSP is even more interesting as it has a large number of applications from direct allocation, incorporated in the routing task (Kouki, Chaar, \& Ksouri, 2009) to DNA problems (Zhong, 2003).

Despite great development of this problem, the TSP remains open for many businesses dealing with wholesale trade. This is mainly due to the fact that the TSP in its standard version seldom occurs. There are often additional constraints that should be taken into account while searching for optimal route for the sales agent visiting sales outlets in the process of products distribution.

The aim of this research consists in formulation and solution of the TSP for a trade business considering the transportation network and possibility of repeated visitation of certain sales outlets. The results of such investigation will enable to reduce transportation expenses of the business' operational activities, and thus - to increase the profitability and competitiveness of the business.

\section{THEORETICAL ASPECTS}

\subsection{The Travelling Salesman Problem}

The TSP is a classical problem of combinatory optimization consisting in the search of the shortest closed route that passes once through all specified points and returns to the initial point. The location $\mathrm{N}$ of the destination points and the matrix of the distances (or transportation costs) C between the points are known. Mathematically this problem can be presented as follows:

$$
\begin{aligned}
& Q(x)=\sum_{i=1}^{N} \sum_{j=1}^{N} c_{i j} x_{i j} \rightarrow \min , \\
& \sum_{i=1}^{N} x_{i j}=1, \forall j=\overline{1, N} \\
& \sum_{j=1}^{N} x_{i j}=1, \forall i=\overline{1, N} \\
& x_{i j} \in\{0,1\} .
\end{aligned}
$$

More detailed information about TSP theory and applications is presented in (Davendra, 2010).

Despite the fact that such problem statement is logical and clear, the TSP is rather hard to be solved; that is why it belongs to the class of NPcomplete problems, i.e. its calculation complexity grows exponentially with the number of parameters. For instance, even for 15 cities the number of routes to be considered in order to find the shortest one is $43,589,145,600$. It is obvious that, while solving the real optimization problems, there is much greater amount of points that should be visited. In such a case, the search for not an optimal solution, but a near optimal one is quite sufficient. Generally, the heuristic methods are used for that. These methods do not guarantee the best decision, but are comparatively fast and produce acceptable solutions due to certain criteria enabling, in some cases, to find the solutions of optimization problems that are impossible to be solved using conventional numerical methods.

The heuristic methods also include genetic algorithms (GA) (Nilsson, 2003) and GA is a variant of meta-heuristic methods, the peculiarity of which lies in careful study of the most perspective parts of the solution space. The quality of the solutions obtained is higher than that of classical heuristics.

\subsection{Application of Genetic Algorithm to Solve the Travelling Salesman Problem}

The main idea of GA was substantiated in the research work by J. Holland (1992) and developed in the monograph by D. Goldberg (1989); the main results and fields of application of genetic algorithms are presented in these works. 
The principle of GA is based on the processes occurring in living nature due to evolution and reproduces $\mathrm{Ch}$. Darwin's idea of natural selection (Bi, Dong, \& Ma, 2012). GA is used for solving optimization problems by random selection, combination and variation of the desired parameters. The solution in GA is represented by the chromosome of the individual in the population (solution set); for the TSP particularly the chromosome is represented by the rearrangement of $n$ numbers (numbers of destination points) in the order of their visitation. GA applies such main genetic operators: reproduction operator, crossover operator, and mutation operator.

\section{EMPIRICAL STUDY - SOLVING THE TRAVELLING SALESMAN PROBLEM WITH GENETIC ALGORITHM}

\subsection{Searching for Shortest Route without Consideration of Transportation Network}

The TSP was formulated and solved on the basis of the materials of a group of commercial businesses of Chernivtsi oblast (Ukraine). The wholesale trade businesses act as mediators between the manufacturers of the products and retail trade businesses, which already work with end consumers. Distribution activity of wholesale trade companies is organized in the following way. The sales agents, working with specific sales outlets, daily visit a certain set of them, and this set is cyclic. Having taken the products order, the agents return to the warehouse. Next day, according to the obtained orders, the goods transport delivers the products to sales outlets.

As the fuel expenses of sales agents are compensated by the company, the task of minimizing the distances covered by the agents, as well as the transportation expenses of the company in the process of its operational activities proves to be interesting. Thus, we have a TSP in its classical form: we must find the shortest route of visiting all the sales outlets per day with the following return to the initial point. The information concerning the lists of sales outlets that should be visited by each agent daily and geographical coordinates of these points is given. The list of sales outlets for the k-th sales agent on the $\mathrm{m}$-th day of the cycle is presented in Table 1.

\section{Table 1. List of sales outlets of the $k$-th sales agent on the $m$-th day of the cycle}

\begin{tabular}{|l|l|l|l|l|l|}
\hline \multirow{2}{*}{ Sales outlets } & \multicolumn{2}{|l|}{$\begin{array}{l}\text { Geographical } \\
\text { coordinates (degrees) }\end{array}$} & \multirow{2}{*}{ Sales outlets } & \multicolumn{2}{l|}{$\begin{array}{l}\text { Geographical } \\
\text { coordinates (degrees) }\end{array}$} \\
\cline { 2 - 3 } & Latitude & Longitude & & Latitude & Longitude \\
\hline Sales outlet No. 1 & 48.2541 & 25.9630 & Sales outlet No. 12 & 48.2601 & 25.9539 \\
\hline Sales outlet No. 2 & 48.2663 & 25.9452 & Sales outlet No. 13 & 48.2569 & 25.9295 \\
\hline Sales outlet No. 3 & 48.2575 & 25.9296 & Sales outlet No. 14 & 48.2646 & 25.9466 \\
\hline Sales outlet No. 4 & 48.2599 & 25.9513 & Sales outlet No. 15 & 48.2581 & 25.9310 \\
\hline Sales outlet No. 5 & 48.2670 & 25.9500 & Sales outlet No. 16 & 48.2637 & 25.9520 \\
\hline Sales outlet No. 6 & 48.2651 & 25.9508 & Sales outlet No. 17 & 48.2644 & 25.9462 \\
\hline Sales outlet No. 7 & 48.2576 & 25.9293 & Sales outlet No. 18 & 48.2642 & 25.9517 \\
\hline Sales outlet No. 8 & 48.2579 & 25.9324 & Sales outlet No. 19 & 48.2603 & 25.9538 \\
\hline Sales outlet No. 9 & 48.2584 & 25.9377 & Sales outlet No. 20 & 48.2667 & 25.9506 \\
\hline Sales outlet No. 10 & 48.2679 & 25.9484 & Sales outlet No. 21 & 48.2624 & 25.9451 \\
\hline Sales outlet No. 11 & 48.2639 & 25.9444 & & & \\
\hline
\end{tabular}

Basing on the above reasoning, it was decided to apply GA for finding the optimal route. For its realization the following basic structural elements were determined: the form of fitness function 
(objective function) and population element, the crossover and mutation process. The form of fitness function corresponds to the objective function in the classical TSP (1.1). The route through all sales outlets was taken as a population element (one possible solution). Each route is a possible solution, though it is not necessarily the shortest one. The optimality of the route is determined by the assessment of fitness function for each population element. The population elements with great fitness function values are discarded (are lost), while those with smaller ones - continue to live. Thus, the average adaptability of the whole population improves. This is the way the selection process occurs. Further the crossover process follows as the stage of formation of new solutions in the population that has passed the selection process to restore its number. In the crossover process two available solutions are taken and their constituent parts (genes) are combined in a new solution that remains within the population. As crossing does not provide the whole amount of variants of genes combinations, the mutation process is necessary, which consists in the fact that for certain solutions there are random changes in the genes. This cycle is fulfilled until the required number of created populations is achieved or some other condition of algorithm stop is fulfilled. The solution found in such a way is not necessarily the best one, but it is close to optimal.

Having set the initial size of population equal 100 and geographical coordinates of sales outlets, we shall obtain the solution of this travelling salesman problem in the following form (Fig. 1).

The first graph of the Figure 1 presents sales outlets that should be visited by the k-th sales agent on the $\mathrm{m}$-th working day of the cycle. The second graph of the Figure 1 presents the obtained closed route of the agent, the initial point of it is denoted by a circlet. The sequence of sales outlets visitation is as follows: $1-4-21-9-8-$ $13-7-3-15-11-17-14-2-10-5-20-$ $6-18-16-19-12-1$. The total distance covered by the agent visiting the sales outlets per day will amount to 0.0828 of a degree that for this geographical latitude corresponds to $5.887 \mathrm{~km}$. This solution was obtained after 1914 iteration of the algorithm.

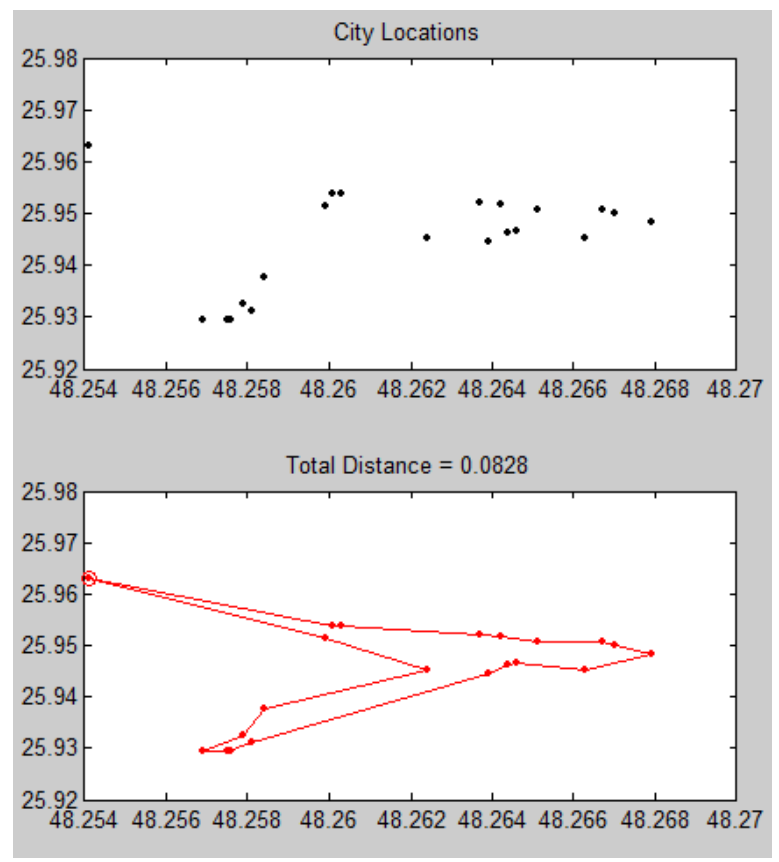

Fig. 1. Sales outlets that should be visited by the k-th sales agent and his modeled near optimal route without consideration of transportation network

The constructed model enables to obtain a near optimal route of passing all destination points within seconds and calculates the total length of the route. However, it does not consider the transportation roads, i.e. it tracks the route "straight". That is why it was decided to build the next model with consideration of transportation network.

\subsection{Searching for Shortest Route with Consideration of Transportation Network}

Let us set up the matrix of distances between each pair of destination points calculated according to the existing roads by means of GIS Google Maps. The solution obtained in such a way after 898 iterations includes the following sequence of visiting the points: $1-12-4-19-16-18-6-$ $20-5-10-2-17-14-21-11-9-8-15-$ $7-3-13-1$, while the total length of the route amounts to $8.947 \mathrm{~km}$, that is by $52 \%$ greater than the result obtained without consideration of transportation roads. 


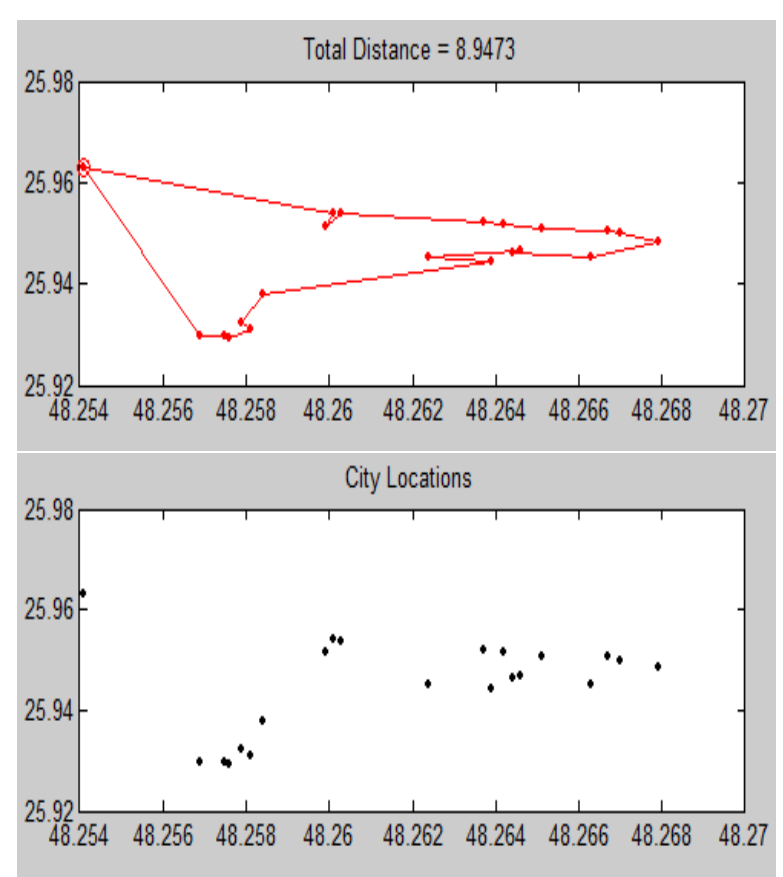

Fig. 2. Sales outlets that should be visited by the $k$-th sales agent and his modeled near optimal route with consideration of transportation network

However, this is an ideal variant. Practically the situations occur, when sales outlets representatives ask the sales agent to come later during the day because of too many customers or lack of time. Then the developed algorithm should be improved taking into account the repeated visit to a certain sales outlet. The main question of interest for us is: How will the total length of the route change then?

\subsection{Searching for Shortest Route with Consideration of Transportation Network and Repeated Visitation of Certain Sales Outlets}

Let us assume that the Sales Outlet No. 6 should be visited once again. Then it is suggested to divide the total set of sales outlets into two subsets: the set of already visited sales outlets (the sales outlets No. 1, 12, 4, 19, 16, 18, 6) and the set of those not yet visited (the sales outlets No. $6,20,5,10,2,17,14,21,11,9,8,15,7,3,1)$. It is obvious that sales outlets No. 1 and 6 belong to both subsets: No. 1 being the initial and final point of the route and No. 6 - due to repeated visitation. The route of the sales agent visitation of the first set of sales outlets is determined and does not change. To calculate the order of visiting the sales outlets not yet attended by the agent, it is necessary to improve the existing algorithm setting the initial point (in our case it is Sales Outlet No. 20) and the final point (Sales Outlet No. 1) of the route excluding the route closeness. The further step consists in combining the two routes in one by adding the routes lengths and the distance between Sales Outlets No. 6 and No. 20.

Thus we have obtained the route of visiting all the sales outlets with repeated visit of Sales Outlet No. 6: $1-12-4-19-16-18-6-20-6-5-10$ $-2-17-14-21-11-9-8-15-7-3-13-$ 1. The route length in this case amounted to 9.458 $\mathrm{km}$, which is $5.71 \%$ greater than the length of the near optimal route with single visitation of all points excluding the first one. Addition of another sales outlet to be visited repeatedly increases the total length of the route by $4.6 \%$.

Moreover, the near optimal route can change because of roadblocks due to road maintenance or traffic jams that require taking the bypass. Taking into consideration all mentioned above we can set the additional $10 \%$ of distance to the length of the near optimal route.

\subsection{Analyzing Results}

The results of comparison of real routes covered by the $k$-th sales agent during every day of the cycle with the near optimal routes calculated using genetic algorithms are presented in Table 2 with consideration of $10 \%$ correction.

Analyzing the data presented in Table 2, one can see that if the days of the cycle are concerned, the deviation is sufficient. For instance, for the $3^{\text {rd }}$ day of the cycle the $\mathrm{k}^{\text {th }}$ sales agent found such an optimal route that the length of the modeled route is only $2.8 \%$ smaller than its real length, and with consideration of $10 \%$ correction it is even greater. On the contrary, on the $6^{\text {th }}$ day of the cycle there is the greatest deviation $59.4 \%$, i.e. the existing route is by 2.5 times longer than the modeled one. The high amplitude of deviations can be conditioned by variation of the amount of points to be visited along the route, as the smallest deviation is recorded for the $5^{\text {th }}$ and $10^{\text {th }}$ days of the cycle, when the amount of points is not more than 9. The greatest deviation is typical for the "busiest" $6^{\text {th }}$ and $7^{\text {th }}$ days, when the amount of points reaches 22 . 
Table 2. Comparison of the lengths of real and modeled routes

\begin{tabular}{|l|c|c|c|r|}
\hline $\begin{array}{c}\text { Days of } \\
\text { cycle }\end{array}$ & $\begin{array}{c}\text { Length of real } \\
\text { route, } \mathrm{km}\end{array}$ & $\begin{array}{c}\text { Length of near } \\
\text { optimal route, } \\
\mathrm{km}\end{array}$ & $\begin{array}{c}\text { Length of near optimal } \\
\text { route, corrected by 10\%, km }\end{array}$ & Error, \% \\
\hline Day 1 & 14.823 & 8.947 & 9.842 & 33.6 \\
\hline Day 2 & 10.100 & 8.573 & 9.430 & 6.6 \\
\hline Day 3 & 10.480 & 10.180 & 11.198 & -6.8 \\
\hline Day 4 & 11.575 & 8.836 & 9.720 & 16.0 \\
\hline Day 5 & 7.754 & 6.813 & 7.494 & 3.3 \\
\hline Day 6 & 20.910 & 7.713 & 8.484 & 59.4 \\
\hline Day 7 & 19.543 & 8.676 & 9.544 & 51.2 \\
\hline Day 8 & 14.630 & 12.680 & 13.948 & 3.6 \\
\hline Day 9 & 15.798 & 9.024 & 9.926 & 3.4 \\
\hline Day 10 & 8.580 & 7.529 & 8.282 & \\
\hline
\end{tabular}

Taking into account everything mentioned above, it can be concluded that the suggested algorithm of solving the TSP for a commercial business enables to find the near optimal route of visiting sales outlets by the sales agent, and the found route is by $28.8 \%$ shorter than the real one.

Thus implementation of the suggested method of finding the near optimal route of visiting sales outlets by the agent in the products distribution process enables the trade businesses to reduce transportation expenses at the average by $28.8 \%$ for each agent per day. Knowing the number of sales agents of the company, it is easy to calculate the profit that optimization of routes of visiting the sales outlets by agents can provide for the company.

\section{CONCLUSIONS}

In this research the travelling salesman problem for wholesale trade businesses was formulated and solved using genetic algorithms. Consideration of transportation network of the region fitted the solution of this problem to reality. Furthermore, the suggested algorithm, as opposed to other available ones, satisfies additional conditions of repeated visitation of certain sales outlets by the agent. The obtained close to optimal route of visiting the sales outlets by the agent is by $28.8 \%$ shorter than the real one. The results of this investigation enable to reduce transportation expenses of the company form its operational activity and, consequently, - to increase the profitability and competitiveness of the company.

Within the further research it is planned to solve the problem of searching the optimal route of products distribution by goods transport taking into account the load-carrying capacity of transportation means as well as other factors.

\section{WORKS CITED}

Bi, S., Dong, X., \& Ma, Y. (2012). The Design and Analysis of TSP Problem Based on Genetic Algorithm and Ant Colony Algorithm. International Journal of Education and Management Engineering, 2(9), 56-60.

Davendra, D. (Ed.). (2010). Travelling Salesman Problem, Theory and Applications. InTech. doi: $10.5772 / 547$

Goldberg, D. E. (1989). Genetic Algorithms in Search, Optimization and Machine Learning. Reading, MA: Addison-Wesley. 
Goodman, S. E., \& Hedetniemi, S. T. (1977). Introduction to the design and analysis of algorithms. McGraw-Hill.

Holland, J. H. (1992). Adaptation in Natural and Artificial Systems. An Introductionary Analysis With Application to Biology? Control and Artificial Intelligence. Cambridge, MA, USA: MIT Press.

Kouki, Z., Chaar, B. F., \& Ksouri, M. (2009). TSP based Evolutionary optimization approach for the Vehicle Routing Problem. 2nd Mediterranean Conference on Intelligent Systems and Automation (pp. 373-376). Melville, N.Y.: American Institute of Physics.

Nilsson, C. (2003). Heuristics for the Traveling Salesman Problem. Retrieved from Technical University Koshice: http://web.tuke.sk/fei-cit/butka/hop/htsp.pdf

Zhong, W. (2003). Using Traveling Salesman Problem Algorithms to Determine Multiple Sequence Alignment Orders. Athens.

Received for publication:

29.09.2014

Revision received:

01.10 .2014

Accepted for publication:

09.12 .2014

\section{How to cite this article?}

Style - APA Sixth Edition:

Matsiuk, N. (2015, Jan 15). Solution of travelling salesman problem for wholesale outlays considering repeated visitation of certain sales outlets. (Z. Čekerevac, Ed.) MEST Journal, 3(1), 120-126. doi:10.12709/mest.03.03.01.14

Style - Chicago Fifteenth Edition:

Matsiuk, Nataliia. 2015. "Solution of travelling salesman problem for wholesale outlays considering repeated visitation of certain sales outlets." Edited by Zoran Čekerevac. MEST Journal (MESTE) 3 (1): 120-126. doi:10.12709/mest.03.03.01.14.

Style - GOST Name Sort:

Matsiuk Nataliia Solution of travelling salesman problem for wholesale outlays considering repeated visitation of certain sales outlets [Journal] // MEST Journal / ed. Čekerevac Zoran. - Belgrade : MESTE, Jan 15, 2015. - 1 : Vol. 3. - pp. 120-126.

Style - Harvard Anglia:

Matsiuk, N., 2015. Solution of travelling salesman problem for wholesale outlays considering repeated visitation of certain sales outlets. MEST Journal, 15 Jan, 3(1), pp. 120-126.

Style - ISO 690 Numerical Reference:

Solution of travelling salesman problem for wholesale outlays considering repeated visitation of certain sales outlets. Matsiuk, Nataliia. [ed.] Zoran Čekerevac. 1, Belgrade : MESTE, Jan 15, 2015, MEST Journal, Vol. 3, pp. 120-126. 